\section{COLITIS IN PNEUMONIA.}

To the Editor of 'THE LANCET.

SIR,-I venture to support Sir W. Hale-White's opinion (THE LANCET, Jan. 22nd, p. 200) that acute colitis is very rare in lobar pneumonia by my own experience of one example only in 558 consecutive cases. I regret that I have no details now to hand of the intestinal symptoms beyond the facts that they appeared during the patient's treatment in hospital and that recovery took place. In three of my cases gastrointestinal disturbance of some kind or other was the presenting symptom, and with Sir W. Hale-White's letter before me I am vividly reminded of one of these, a man aged 38, who upon the usual interrogation at his admission into the ward said: "For two days I have been suffering with the bloody flux." (He was, I think, a student of old English literature.) This patient had a temperature of $103 \cdot 6^{\circ} \mathrm{F}$. without physical signs of any description beyond the passage of comparatively fresh blood by the bowel. I confess that the possibility of pneumonia did not occur to me, but, exactly as in Sir W. Hale-White's case, within a short time unequivocal signs of consolidation with rusty sputum developed.

Sir W. Hale-White's letter was prompted by an article in your issue of Jan. 15th by Dr. E. Cronin Lowe upon three cases of influenzal pneumonia. In this Dr. Lowe refers to a publication by my colleagues, Dr. Herbert French and Dr. N. F. Hallows, and myself, and says that although we mention the normality of the appendix and bowel generally in our autopsies we do not definitely state whether the bowel was examined in detail throughout. We mentioned the appendix specifically in view of the statements that had appeared that there was a tendency for influenzo-pneumonic patients to develop acute appendicitis and so to emphasise that such was not the case in our experience. As for the alimentary canal as a whole we were satisfied to state that it exhibited no particular change, and I may now add that the whole length was examined critically by Dr. French, which is a guarantee of thorough investigation and of accurate pathological interpretation, in a large proportion of our earlier autopsies, a procedure subsequently neglected in view of the persistently negative findings. This, of course, does not eliminate the possibility of cases with ulceration or necrosis of the bowel having actually occurred and which would have been detected if systematically investigated for, as Dr. Lowe says, the peritoneum gives no evidence of such inflammatory change in the bowel itself. But when one recalls the remarkable seasonal and local peculiarities exhibited by crops of influenzo-septicæmic cases I think it more likely that Dr. Lowe's cases were of a special type.-I am, Sir, yours faithfully,

ADOLPHE ABRAHAMS.

Park-crescent, Portland-place, W., Jan. 25th, 1921.

\section{BILHARZIA-INFESTED SNAILS AND THEIR EMPLOYMENT AS ANTIGEN.}

To the Editor of THE LANCET.

SIR,-Although the dams along the course of the rivers of Natal and the many stagnant pools that are produced by the floods swarm with fresh-water snails and other evidences of stream-pollution, the collecting of sufficient numbers of the various species which harboux parasites requires much patient search, and a great deal of success depends upon the state of the weather and wind. At this season of the year about 1 in 6 Physopsis africana are infested with schistosomes. Only a small proportion of infested specimens harbour the parasite which causes bilharzia disease in man, a greater number being infested with cercariæ which develop into Schistosoma bovis. I have found schistosomes developing in Isidora tropica, Isidora forskali, Isidora schackoi jickeli, Physopsis africana, Limncea natalensis, and Planorbis pfeifferi, but have not yet secured the adult forms of any besides $S$. hamatobium and S. bovis.

Dr. W. A. Murray has prepared a very efficient antigen from the livers of Physopsis africana, which haxbour these schistosomes. This has involved the dissection of a large number of specimens; for at least $15 \mathrm{gr}$. of infested liver-substance is needed in the preparation of the antigen for the complement-fixation test. But livers harbouring the cercariæe of $S$. bovis appear to be just as useful as those infested with the cercariæ of $S$. hamatobium. Besides giving a positive reaction in patients who harbour the more common bilharzia parasites, the test has given a positive reaction in a patient from China, whose fæces contain the typical unspined eggs of $S$. japonicum. This blood-test, introduced by Dr. Hamilton Faixler, promises to be of even greater value in the diagnosis of Schistosomum bovis. The spindle-shaped eggs that I have seen in guinea pigs experimentally infested with this parasite are on an average 0.175 by $0.04375 \mathrm{~mm}$. in diameter. These para. sites do not appear to cause as much bleeding as is common in persons infested with $S$. hamatobium, and the diagnosis of their presence in cattle and the effect of appropriate treatment will be decided very largely by the reaction of the serums to the antigen test.

On Oct. 19th I asked Dr. Murray to apply the test to the serums of seven sheep that are known to harboar liver-flukes and are now undergoing a course of injections for this complaint; a positive reaction was obtained in each case. An antigen prepared from freshwater snails infested with schistosomes may, therefore, be used in the diagnosis of bilharzia and fasciola disease in man and beast.

I am, Sir, yours faithfully,

F. G. CAwston, M.D. Cantab., First Streatfeild Research Scholar.

Durban, S. Africa, Nov. 15th, 1920.

\section{A SIMPLE METHOD OF GROWING THE ACNE} BACILLUS.

\section{To the Editor of THE LANCET.}

SIR,-Having experienced some difficulty in separating the acne bacillus from the staphylococci which usually accompany it in comedoes and acne lesions by such methods as are known to me, the following procedure has been found to afford an easy means of effecting the separation and of growing the bacillus without trouble.

The medium consists of ordinary peptone broth to which is added 1 per cent. of oleic acid and 1 per cent. of glucose. About $10 \mathrm{c.cm}$. of the medium is distributed in each tube, and a layer of melted vaseline is run on the surface of the broth. The tubes are then sterilised. A suspension of a comedo crushed in a little normal salt is introduced with a pipette into the medium. The opening thus made in the vaseline is sealed by the application of heat so as to render the cultures anaerobic. After incubating the inoculated tube at $37^{\circ} \mathrm{C}$. for four days large numbers of acne bacilli will be found to be present. At this date, in such an environment, the acne bacilli usually outnumber the staphylococci, the growth of which appears to be restrained, and a pure culture is readily obtainable in the usual manner. By concentration of the growth by centrifugalisation from a number of such anaerobic cultures acne bacilli can be obtained in considerable quantities.

I am, Sir, yours faithfully,

W. E. DE KorTÉ, M.B. Lond.

Cape Town, Nov. 17th, 1920

\section{MITES AS INTERNAL PARASITES IN MAN.}

\section{To the Editor of THE LANCET.}

SIR, - Re the occurrence of mites as internal parasites in man, discussed at the last meeting of the Medical Society of London and reported in THE LANCE'T of Jan. 22nd (p. 175), it is interesting to note an article by Mr. R. J. Pye-Smith ${ }^{1}$ in which it is stated that he drew off in July, 1899, fluid from a testicular cyst of a patient who some years previously had spent a short time in India, and whilst there had been catheterised for retention of urine in an attack of fever. This fluid was examined by Dr. C. Munro Hector, who found numerous living acari, shed skins, and ova. Unable to identify them, Dr. Hector consulted Mr. A. Denny, F.L.S., who 